\title{
Farnesyl pyrophosphate synthase inhibitor, ibandronate, improves endothelial function in spontaneously hypertensive rats
}

\author{
JIE HAN $^{1^{*}}$, DONG-MEI JIANG ${ }^{2 *}$, YANG YE ${ }^{2}$, CHANG-QING DU ${ }^{3}$, JIAN YANG $^{1}$ and SHEN-JIANG HU ${ }^{1}$ \\ ${ }^{1}$ Department of Cardiology, The First Affiliated Hospital, College of Medicine, Zhejiang University, Hangzhou, \\ Zhejiang 310003; ${ }^{2}$ Department of Cardiology, Sir Run Run Shaw Hospital, College of Medicine, Zhejiang University, \\ Hangzhou, Zhejiang 310016; ${ }^{3}$ Department of Cardiology, Zhejiang Hospital, Hangzhou, Zhejiang 310013, P.R. China
}

Received April 9, 2015; Accepted February 17, 2016

DOI: $10.3892 / \mathrm{mmr} .2016 .5025$

\begin{abstract}
Reactive oxygen species (ROS), originating predominantly from vascular smooth muscle cells (VSMCs), lead to vascular damage and endothelial dysfunction in rats with hypertension. The downstream signaling pathways of farnesyl pyrophosphate (FPP) synthase, Ras-related C3 botulinum toxin substrate 1 (Racl) and nicotinamide adenine dinucleotide phosphate (NADPH) oxidase, mediate the generation of ROS. The present study investigated the effect of the FPP synthase inhibitor, ibandronate, on ROS production, the possible beneficial effect on endothelial dysfunction and the underlying mechanisms in spontaneously hypertensive rats (SHRs). The SHRs were treated with ibandronate for 30 days. Endothelium-dependent and independent vasorelaxation were measured in isolated aortic rings. Additionally, VSMCs from the SHRs and Wistar-Kyoto (WKY) rats were cultured. The production of ROS and activation of NADPH oxidase were determined using fluorescence and chemiluminescence, respectively, in vivo and in vitro. Angiotensin II (Ang II) increased ROS production in the cultured VSMCs from the WKY rats and SHRs, in a concentration-dependent manner. The Ang II-induced responses were more marked in the SHR VSMCs, compare with those in the WKY VSMCs, however, the response decreased significantly following ibandronate pretreatment. Treatment with ibandronate significantly decreased the production of ROS, translocation of NADPH oxidase subunit p47phox, and activities of NADPH oxidase and Rac1 in the aorta and VSMCs, and improved the impaired endothelium-dependent vasodilation in the SHRs. Adding
\end{abstract}

Correspondence to: Dr Shen-Jiang Hu, Department of Cardiology, The First Affiliated Hospital, College of Medicine, Zhejiang University, 79 Qingchun Road, Hangzhou, Zhejiang 310003, P.R. China

E-mail: s0hu0001@hotmail.com

*Contributed equally

Key words: ibandronate, reactive oxygen species, nicotinamide adenine dinucleotide phosphate oxidase, Ras-related $\mathrm{C} 3$ botulinum toxin substrate 1 , vascular smooth muscle cells geranylgeraniol, but not farnesol or mevalonate, reversed the inhibitory effects of ibandronate. In addition, inhibiting geranylgeranyl-transferase mimicked the effect of ibandronate on the excess oxidative response. Ibandronate exerted cellular antioxidant effects through the Rac1/NADPH oxidase pathway. These effects may have contributed to the vasoprotective effects on the impaired endothelium in SHRs.

\section{Introduction}

A common feature of endothelial dysfunction is the reduced bioavailability of nitric oxide (NO) due to reduced endothelial NO synthase (eNOS) activity and the rapid reaction between NO with superoxide anions $\left(\mathrm{O}_{2}-\right)$ produced in the vasculature (1). The increased release and production of reactive oxygen species (ROS) in hypertension is also considered to be a key event in the pathogenesis of endothelial dysfunction $(2,3)$.

ROS, including $\mathrm{O}_{2}$ - and hydrogen peroxide, are produced primarily by nicotinamide adenine dinucleotide phosphate (NADPH) oxidase, which resides in vascular smooth muscle cells (VSMCs), endothelial cells and white blood cells (4-6). This enzyme is composed of several subunits, including membrane-bound flavo-cytochrome b558 (Nox1, Nox2 [formerly gp91phox], Nox3, Nox4, Nox5, dual oxidase 1 [Duox1], Duox2 and p22phox) and three cytoplasmic subunits termed p47phox, p67phox and p40phox (6-8). The activation of NADPH oxidase is initiated by the translocation of the cytosolic components, p47phox, p67phox and GTPase Ras-related C3 botulinum toxin substrate 1 (Racl) to the membrane (9-11).

Bisphosphonates inhibit farnesyl pyrophosphate (FPP) synthase, a key enzyme in the mevalonate (MEV) pathway (12), by inhibiting isoprenylation, including farnesylation and geranylgeranylation, and preventing the synthesis of various isoprenoids, including FPP and geranylgeranyl pyrophosphate (GGPP) $(13,14)$. The latter is required for the protein isoprenylation of Rac1 for activation $(15,16)$. In our previous studies, it was found that the expression of FPP synthase is significantly upregulated in spontaneously hypertensive rats (SHRs) (17). Therefore, it was hypothesized that the increased synthesis of FPP and GGPP contributes to the excess generation of ROS observed in SHRs.

Inhibiting FPP synthase improves endothelial function in SHRs, as well as upregulating the expression of eNOS 
by suppressing small GTPase Ras homolog (Rho)A activation, which also requires geranylgeranylation by GGPP (18). However, the interaction between FPP synthase and endothelial function through the regulation of ROS in SHRs remains to be elucidated. As alterations in either the production or elimination of ROS affect endothelial function, the present study hypothesized that inhibiting FPP synthase with the bisphosphonate inhibitor, ibandronate, may potentially lead to an interaction with the gene products involved in these processes. Therefore, the present study was designed to determine whether inhibiting FPP synthase improves endothelial function in SHRs, at least in part, via the Rac1/NADPH oxidase pathway. In addition, the effect of ibandronate on ROS production and the expression levels of NADPH oxidase subunits were investigated in cultured VSMCs and aortas from SHRs.

\section{Materials and methods}

Drugs. Ibandronate sodium (IBAN), MEV, apocynin, geranylgeraniol $(\mathrm{GGOH})$ and farnesol $(\mathrm{FOH})$ were obtained from Sigma-Aldrich (St. Louis, MO, USA). Clostridium botulinum C3 exoenzyme was obtained from Biomol Research Laboratories, Inc. (Plymouth Meeting, PA, USA). Y-27632, GGTI-286 and an InSolution Rac1 inhibitor were purchased from Merck Millipore (Darmstadt, Germany). All other materials were commercial products of the highest grade available.

Animal preparations. Male SHRs and Wistar-Kyoto (WKY) rats (10-week-old; Shanghai Laboratory Animal Center of the Chinese Academy of Sciences, Shanghai, China) were housed at $24 \pm 2{ }^{\circ} \mathrm{C}$ with $60 \pm 20 \%$ relative humidity, on a $12: 12$-h light:dark cycle. The animals were provided with a diet of standard chow and water ad libitum, and were treated with IBAN (1 mg/kg) daily by oral gavage or a corresponding quantity of vehicle (0.9\% saline) (18). A total of 20 SHRs were randomly divided into two groups, consisting of an SHR control group and an SHR+IBAN treatment group, and 10 age-matched WKY rats were also used as a control. Treatment was started when the rats were 10 weeks of age and was continued for 30 days. Tissues for subsequent assays and primary cell cultures were isolated from the rats following sacrifice with an overdose of anesthetic (isoflurane $>20 \%$; Sigma-Aldrich) and confirmation by cervical dislocation. The present study was approved by the Institutional Council for Animal Research of Zhejiang University (Hangzhou, China) and the ethics committee of The First Affiliated Hospital, College of Medicine, Zhejiang University, and was performed according to the Guide for the Care and Use of Laboratory Animals, as used and promulgated by the United States National Institutes of Health (19).

Tissue processing and vasomotor experiments. The descending thoracic aorta was dissected from each mouse and placed carefully in chilled Krebs-HEPES buffer (Sigma-Aldrich), containing $\mathrm{NaCl}(118 \mathrm{mM}), \mathrm{KCl}(4.75 \mathrm{mM}), \mathrm{NaHCO}_{3}(25 \mathrm{mM})$, $\mathrm{MgSO}_{4}(1.2 \mathrm{mM}), \mathrm{CaCl}_{2}(1.8 \mathrm{mM}), \mathrm{KH}_{2} \mathrm{PO}_{4}(1.2 \mathrm{mM})$ and glucose $(11 \mathrm{mM})$. Following the removal of excess fat and connective tissue, a $10-\mathrm{mm}$ segment was immediately frozen in liquid nitrogen and stored at $-80^{\circ} \mathrm{C}$ until use in immunoblot or biochemical analyses. Another 5-mm segment was placed in Krebs-HEPES buffer aerated with $95 \% \mathrm{O}_{2}$ and $5 \% \mathrm{CO}_{2}$, and incubated at $37^{\circ} \mathrm{C}$ to measure the levels of ROS in the intact vessel segments. A third segment was cut into 3-4 mm rings and then mounted in an organ bath system (Med Lab 6.0 polygraph; Nanjing Medease Technology Co., Ltd., Nanjing, China) for vasomotor investigations. The aortic rings were equilibrated for 90 min under a resting tension of $2 \mathrm{~g}$ in Krebs-HEPES buffer aerated with $95 \% \mathrm{O}_{2}$ and $5 \% \mathrm{CO}_{2}$. The aortic rings were precontracted with phenylephrine (PE; $\left.10^{-5} \mathrm{M}\right)$. In certain experiments, the arteries were pre-incubated with GGOH $\left(3 \times 10^{-5} \mathrm{M}\right)$, FOH $\left(3 \times 10^{-5} \mathrm{M}\right)$ or $\mathrm{MEV}\left(10^{-4} \mathrm{M}\right)$ for $2 \mathrm{~h}$ at $37^{\circ} \mathrm{C}$ prior to being contracted with PE. Subsequently, endothelium-dependent vasorelaxation was measured in response to cumulative logarithmically increasing concentrations of acetylcholine ( $\mathrm{ACh} ; 10^{-9}-10^{-5} \mathrm{M}$ ), whereas endothelial independent relaxation was investigated using sodium nitroprusside (SNP; $10^{-9}-10^{-5} \mathrm{M}$ ). This effect was compared with those obtained in the presence of GGTI-286, an inhibitor of geranylgeranyl transferase-I $\left(10^{-5} \mathrm{M}\right)(20)$; C3 exoenzyme, Rho inhibitor (30 ng/ml) (21); Y-27632, a RhoA downstream effector Rho-associated kinase (ROCK) inhibitor $\left(10^{-5} \mathrm{M}\right)(22)$; Rac1 inhibitor $\left(10^{-4} \mathrm{M}\right)$; or apocynin (Sigma-Aldrich), an NADPH oxidase inhibitor $\left(10^{-4} \mathrm{M}\right)(23,24)$. ACh-induced relaxation was also examined in the absence or presence of the NOS inhibitor, N $\omega$-nitro-L-arginine methyl ester (L-NAME; $10^{-4} \mathrm{M}$; Sigma-Aldrich) (25). The aortic rings were incubated with L-NAME for 20 min following treatment with GGTI-286, C3 exoenzyme, Y-27632, Rac1 inhibitor or apocynin. The drugs were removed by washing with Krebs-HEPES buffer prior to addition of PE. All results are expressed as a percentage of the maximal contraction tension induced by the preceding PE application.

Smooth muscle cell culture. Primary VSMC cultures were isolated from the thoracic aorta of 10-week-old WKY rats and SHRs by elastase/collagenase digestion, according to the procedure of Battle et al (26). Adventitiae was placed in a tube containing $5 \mathrm{ml}$ collagenase $(0.2 \%$ from a crude powder of 624 U/mg; Eurobio Laboratories, Les Ulis, France) dissolved in medium 199 (Boehringer Ingelheim Pharm GmbH \& Co., Ingelheim, Germany), placed into a water bath and agitated at $37^{\circ} \mathrm{C}$ for $1 \mathrm{~h}$. The cell suspension was then filtered on a sterile porous nylon membrane and washed with $20 \mathrm{ml}$ warm Hanks balanced salt solution to dislodge single cells from fragments. The cell suspension was centrifuged $(500 \mathrm{x} g$ for $5 \mathrm{~min}$ ) and the cell pellet resuspended in culture medium (Gibco; Thermo Fisher Scientific, Inc., Waltham, MA, USA). The quiescent VSMCs were stimulated with angiotensin II (Ang II; Sigma-Aldrich)) for $3 \mathrm{~h}$ at $37^{\circ} \mathrm{C}$. In certain experiments, the cells were pre-exposed for $24 \mathrm{~h}$ at $37^{\circ} \mathrm{C}$ to IBAN $\left(10^{-5} \mathrm{M}\right)$, IBAN+GGOH $\left(3 \times 10^{-5} \mathrm{M}\right)$, IBAN+FOH $\left(3 \times 10^{-5} \mathrm{M}\right)$, IBAN+MEV $\left(10^{-4} \mathrm{M}\right)$, GGTI-286, the selective inhibitor of GGTase I $\left(10^{-5} \mathrm{M}\right)$ or Rac1 inhibitor $\left(10^{-4} \mathrm{M}\right)$.

Measurement of ROS production. The ROS levels were quantitatively measured using a Cell (GMS10016.2 v.A) or Tissue ROS Assay kit (GMS10016.3 v.A) (Genmed Scientifics, Inc., Wilmington, DE, USA), as described previously (27). The quiescent VSMCs were washed twice with incubation media, which consisted of phenol red-free-Dulbecco's modified Eagle's 
medium and $0.1 \%$ bovine serum albumin (both purchased from Sigma-Aldrich). ROS generation was measured in unstimulated cells and in the cells from the WKY rats and SHRs, which were exposed to increasing concentrations of Ang II $\left(10^{-8}-10^{-6} \mathrm{M}\right)$. Additionally, VSMCs from the SHRs were preincubated with vehicle, IBAN, IBAN+GGOH, IBAN+FOH, IBAN+MEV, GGTI-286 or Rac1 inhibitor, as described above. Following the 24-h pre-incubation period, the VSMCs were washed twice and stimulated with Ang II for $3 \mathrm{~h}$, prior to being loaded with 2',7'-dichlorodihydrofluorescein diacetate $(10 \mu \mathrm{M}$; Genmed Scientific, Inc.). After $20 \mathrm{~min}$, the cells were washed with phosphate-buffered saline (PBS). Fluorescence was measured on a Spectra-Max fluorometer (Thermo Fisher Scientific, Inc.) using an excitation wavelength of $488 \mathrm{~nm}$ and an emission wavelength of $525 \mathrm{~nm}$. Images were captured from five randomly selected fields under a fluorescence microscope (IX71; Olympus Corporation, Tokyo, Japan).

The aortic tissues from each group were homogenized using lysis buffer, and $200 \mu \mathrm{g}$ of the homogenized solutions were used to determine protein concentrations using a Bicinchoninic Acid (BCA) Protein Assay kit (Beyotime Institute of Biotechnology, Shanghai, China). The levels of ROS were then quantitatively measured fluorometrically using the Cell and Tissue ROS Assay kits, with excitation at $488 \mathrm{~nm}$ and emission at $525 \mathrm{~nm}$.

Measurement of NADPH oxidase activity. A proportion of the supernatant from the homogenized solutions extracted from cells and aortas were used to determine NADPH oxidase activity. Protein content was determined using a BCA protein assay kit (Beyotime Institute of Biotechnology). The activities of NADPH oxidase were evaluated spectrophotometrically or chemiluminogenically using an NADPH Oxidase Activity Assay kit (GMS50095.2 v.A; Genmed Scientifics, Inc.), as described previously (28).

Racl activation assay. Rac1 GTPase is considered to be important for activating NADPH oxidase and for free radical release, and Rac1 is post-translationally geranylated. Therefore, the effects of Ang II and IBAN on the activity and expression of Rac1 were assessed. Rac1 activity was determined using a pull-down assay, according to the manufacturer's protocol, using a Rac1 Activation Assay Biochem kit (BK035; Cytoskeleton, Inc., Denver, CO, USA). In brief, $10^{7}$ cells were grown in 10-cm dishes, washed in cold PBS and lysed. A protein assay was performed prior to the pull-down assay to equalize the total protein concentrations in each treatment group. Glyceraldehyde-3-phosphate dehydrogenase (GAPDH) protein was used as an internal control. The cell lysates were incubated for $60 \mathrm{~min}$ at $4^{\circ} \mathrm{C}$ with $10-\mu 1$ PAK-PBD-agarose to precipitate the GTP-bound Rac1. The precipitated complexes were washed three times with wash buffer $(25 \mathrm{mM}$ Tris, $\mathrm{pH} 7.5,30 \mathrm{mM}$ $\mathrm{MgCl}_{2}$ and $40 \mathrm{mM} \mathrm{NaCl}$ reconstituted in $100 \mathrm{ml}$ sterile distilled water) and resuspended in $30 \mu \mathrm{l}$ of $2 \mathrm{X}$ Laemmli buffer $(125 \mathrm{mM}$ Tris, pH 6.8, 20\% glycerol, 4\% SDS, $0.005 \%$ bromophenol blue and $5 \%$ beta-mercaptoethanol). Protein concentrations were determined using a BCA Protein Assay kit. The total lysates and precipitates (100 ng samples) were analyzed using 12\% sodium dodecyl sulfate-polyacrylamide gel electrophoresis as previously described (17). Protein was then transferred onto a polyvinylidene difluoride membrane (Bio-Rad Laboratories, Inc., Hercules, CA, USA) that was blocked with 5\% non-fat milk at room temperature for $1 \mathrm{~h}$. The blots were then incubated with anti-Rac1 (1:1,000 dilution; sc-95; Santa Cruz Biotechnology, Inc., Dallas, TX, USA) anti-p47phox (1:1,000 dilution; sc-7660; Santa Cruz Biotechnology) and anti-GAPDH (1:2,500; ab9485; Abcam, Cambridge, UK) primary antibodies overnight at $4{ }^{\circ} \mathrm{C}$, followed by washing with Tris-buffered saline with $0.1 \%$ Tween (Beijing Solarbio Science \& Technology Co. Ltd., Beijing, China) for 10 min 3 times. Then, the blots were incubated with horseradish peroxidase-conjugated goat anti-rabbit immunoglobulin G ( $\operatorname{IgG}$ ) (1:3,000 dilution; ab6721; Abcam), rabbit anti-goat $\mathrm{IgG}$ peroxidase (1:8,000 dilution; A5420; Sigma-Aldrich) and goat anti-mouse IgG (1:2,000 dilution; HA1006; Hangzhou HuaAn Biotechnology Co., Ltd., Huangzhou, China) secondary antibodies at room temperature for $1 \mathrm{~h}$. The densities of bands were quantified by densitometry using Multi Gauge software (version 3.0.1.5; Fujifilm, Tokyo, Japan). Western blot analysis of the total level of Racl in the supernatant was performed for comparison with Rac1 activity, the level of GTP-bound Rac1, in the same samples.

Statistical analysis. All values are expressed as the mean \pm standard error of the mean. The concentration-response curves resulting from the vasomotor experiments were analyzed by nonlinear regression (curve fit). Statistical significance was determined using one-way analysis of variance, followed by the least significant difference post-hoc test. $\mathrm{P}<0.05$ was considered to indicate a statistically significant difference.

\section{Results}

Ex vivo vasomotor experiments. Endothelium-dependent vasorelaxation with increasing concentrations of $\mathrm{ACh}$, and endothelium-independent relaxation exerted by SNP are shown in Fig. 1. ACh-induced relaxation in the arteries was significantly more marked in the WKY rats, compared with the SHRs (Fig. 1A). The arteries of the SHRs exhibited noticeable endothelial dysfunction, and only marginal vasodilation, even at higher ACh concentrations. At $10^{-5} \mathrm{M}$ $\mathrm{ACh}$, the control arteries of the WKY rats were relaxed to $91.1 \pm 3.5 \%$ and arteries of SHRs were relaxed to $37.8 \pm 2.9 \%$. No significant effect was observed among the groups induced by SNP (Fig. 1B). In addition, treatment with IBAN did not alter endothelium-independent vasorelaxation, but it markedly increased ACh-induced maximal vasodilatation to $60.7 \%$ ( $\mathrm{P}<0.05$, vs. SHR group), suggesting a marked improvement of endothelial dysfunction in the SHRs. Following pre-incubation with GGOH $\left(3 \times 10^{-5} \mathrm{M}\right)$, ACh-induced maximal relaxation in the SHR-IBAN group decreased to $45.1 \%$ ( $\mathrm{P}<0.05$, vs. absence of GGOH; Fig. 1C). However, neither pretreatment with MEV nor FOH at $3 \times 10^{-5} \mathrm{M}$ and $10^{-4} \mathrm{M}$, respectively, improved ACh-induced relaxation in the SHR-IBAN group (Fig. 1D and E). Pretreatment with GGTI-286, C3 exoenzyme, Y-27632, Rac1 inhibitor or apocynin $\left(10^{-5} \mathrm{M}, 30 \mathrm{ng} / \mathrm{ml}, 10^{-5} \mathrm{M}\right.$, $10^{-4} \mathrm{M}$ and $10^{-4} \mathrm{M}$, respectively), mimicked the improved effect of IBAN on ACh-induced relaxation, but did not significantly change the inhibition caused by L-NAME (10-4 M; Fig. 2). Treatment with L-NAME eliminated ACh-induced relaxation in the aortic rings from the SHR groups (Figs. 1A and 2). 
A

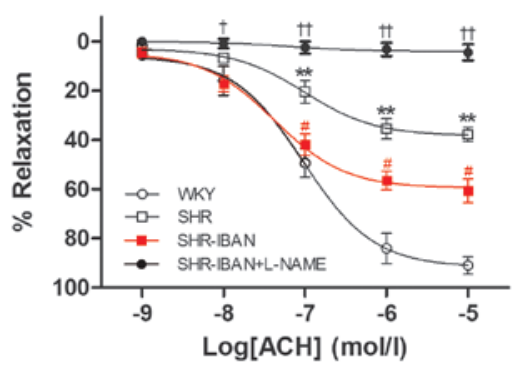

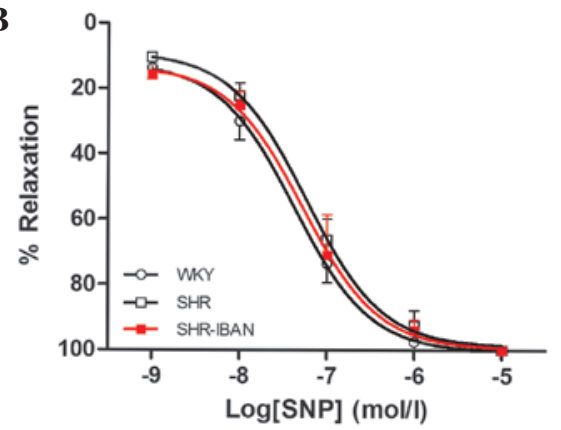

C

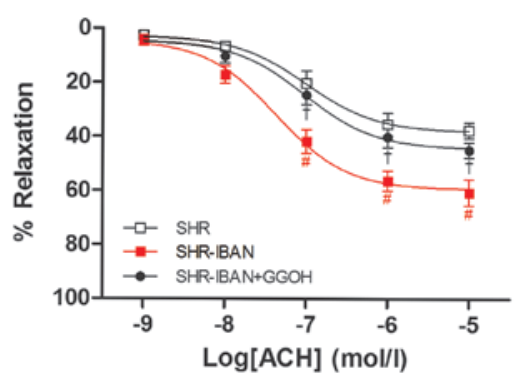

D

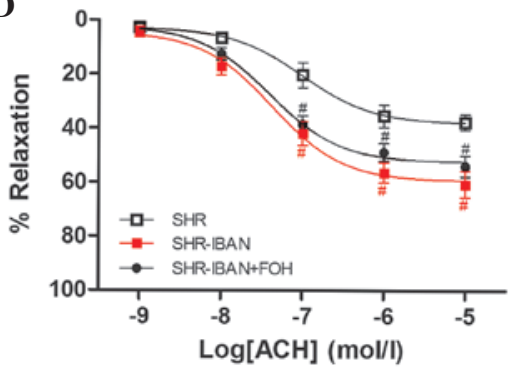

$\mathbf{E}$

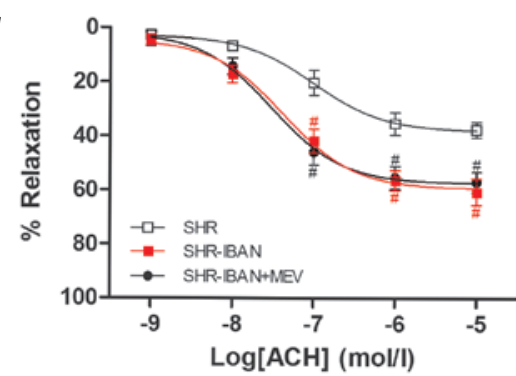

Figure 1. Effect of IBAN treatment on endothelium-dependent and -independent vasorelaxation. (A) Endothelium-dependent relaxations induced by Ach.

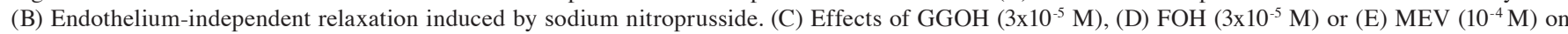
endothelium-dependent relaxation were assessed in isolated aortic rings from IBAN-treated SHRs. Values are presented as the mean \pm standard error of the mean from five rats. ${ }^{* *} \mathrm{P}<0.01$, vs. WKY group; ${ }^{*} \mathrm{P}<0.05$ vs. SHR group; ${ }^{\dagger} \mathrm{P}<0.01$ vs. SHR-IBAN group; ${ }^{\dagger} \mathrm{P}<0.05$ vs. SHR-IBAN group. SHRs, spontaneously hypertensive rats; WKY rats, Wistar-Kyoto rats; IBAN, ibandronate; Ach, acetylcholine; GGOH, geranylgeraniol; FOH, farnesol; MEV, mevalonate.

A

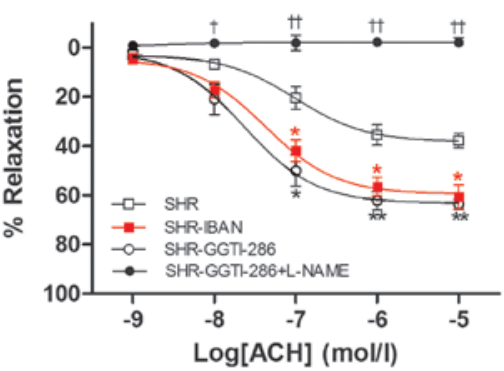

B

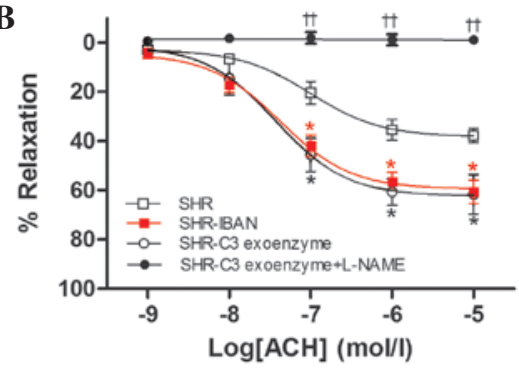

C

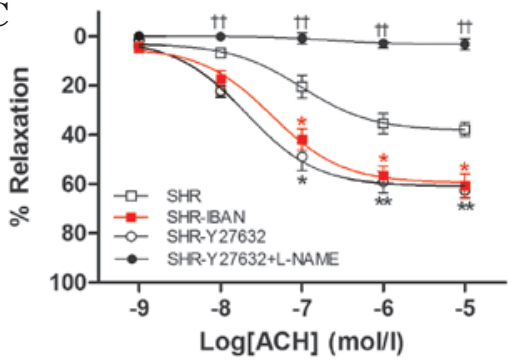

D

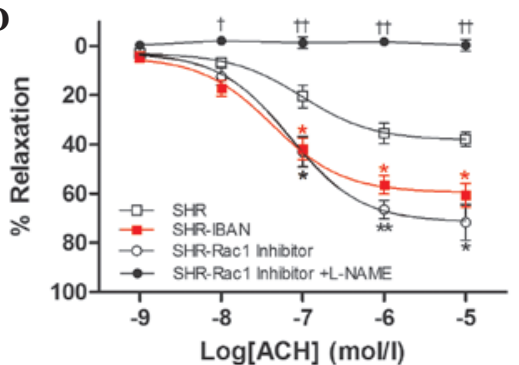

$\mathbf{E}$

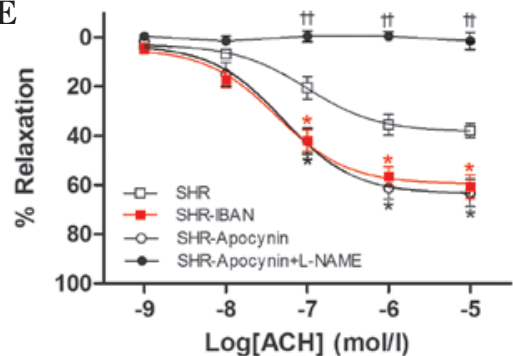

Figure 2. Effect of (A) GGTI-286 (10 $\left.0^{-5} \mathrm{M}\right)$, (B) C3 exoenzyme (30 ng/ml), (C) Y-27632 (10-5 M), (D) Rac1 inhibitor (10 $\left.{ }^{-4} \mathrm{M}\right)$ and (E) apocynin (10 $\left.0^{-4} \mathrm{M}\right)$ on the endothelium-dependent contractile effects of Ach in the absence and presence of L-NAME-treated arteries from SHRs. Values are presented as the mean \pm standard error of the mean from five rats. ${ }^{* *} \mathrm{P}<0.01$, vs. SHR group; ${ }^{*} \mathrm{P}<0.05$, vs. SHR group; ${ }^{\dagger \dagger} \mathrm{P}<0.01$. vs. SHRs treated with GGTI-286, C3 exoenzyme, Y-27632, Rac1 inhibitor or apocynin; 'P<0.05, vs. SHR treated with GGTI-286, C3 exoenzyme, Y-27632, Rac1 inhibitor or apocynin. SHRs, spontaneously hypertensive rats; WKY rats, Wistar-Kyoto rats; L-NAME, N $\omega$-nitro-L-arginine methyl ester; Ach, acetylcholine.

Ang II induces an increase in the generation of ROS in VSMCs. The generation of ROS was measured in the unstimulated cells. Ang II induced a concentration-dependent increase in fluorescence, and the maximal responses were observed at $10^{-7} \mathrm{M}$ in the VSMCs from the SHRs and WKY rats (Fig. 3A). In addition, the responses to Ang II were significantly higher in the SHRs, compared with those in the WKY rats.

IBAN reduces the production of ROS in SHR VSMCs and aortas. To evaluate the effect of IBAN on the intracellular production of ROS, the SHR VSMCs were pre-incubated for 
A

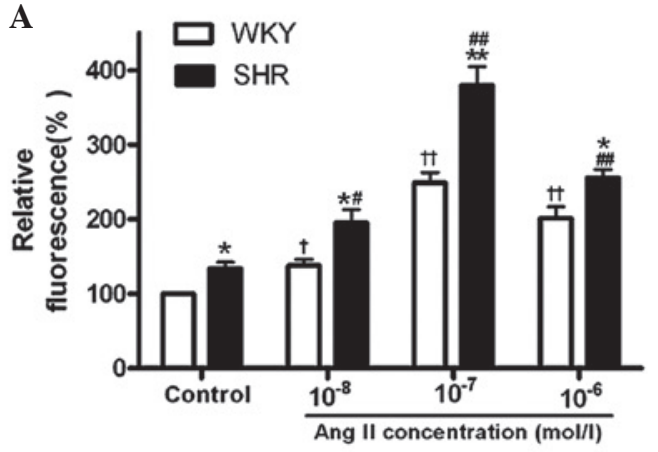

C

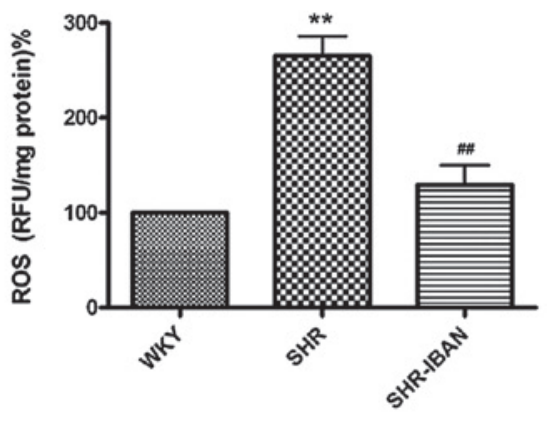

$\mathbf{E}$

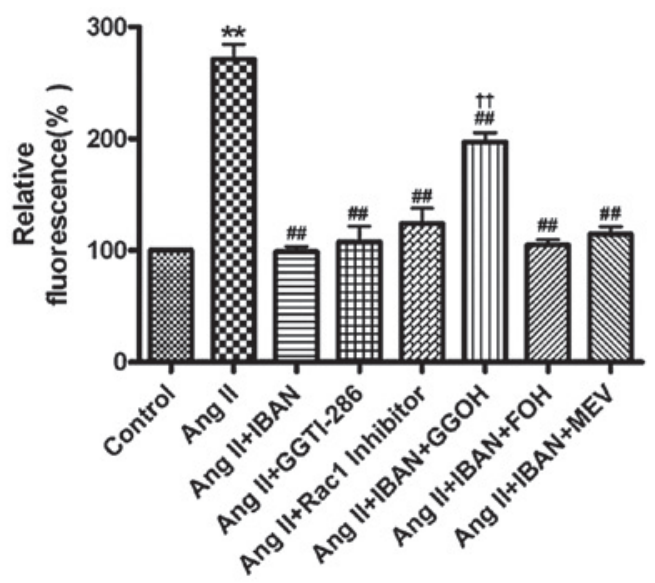

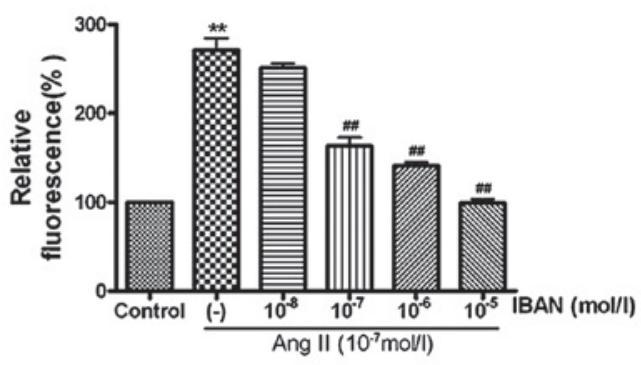

$\mathbf{D}$
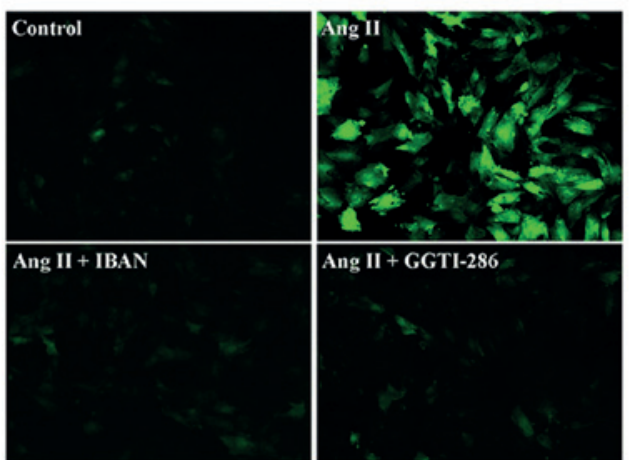

Ang II + GGTI-286
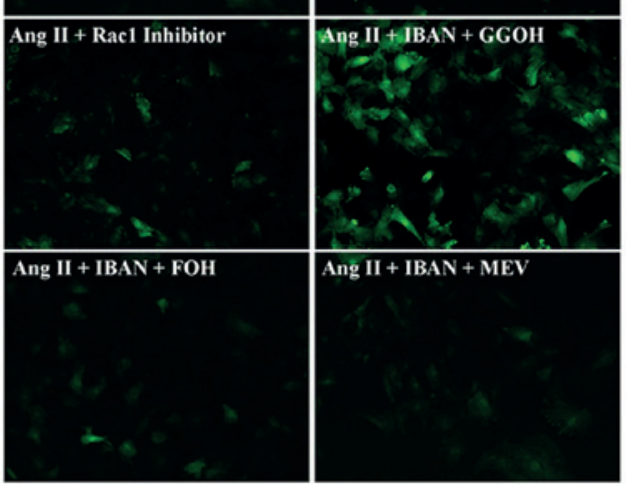

Figure 3. Effects of IBAN on production of ROS in Ang II-induced VSMCs and aortas. (A) Treatment with Ang II induced a concentration-dependent increase in relative fluorescence in the VSMCs from the SHRs and WKY rats. (B) VSMCs from the SHRs were pre-incubated with IBAN (10 $\left.{ }^{-8}-10^{-5} \mathrm{M}\right)$ for $24 \mathrm{~h}$ and then incubated with or without Ang II $\left(10^{-7} \mathrm{ML}\right)$ for $3 \mathrm{~h}$. (C) ROS levels were assessed in isolated aortic segments of the WKY rats and IBAN-treated SHRs. (D and E) Effects of IBAN $\left(10^{-5} \mathrm{M}\right)$, GGTI-286 $\left(10^{-5} \mathrm{M}\right)$, Rac1 inhibitor $\left(10^{-4} \mathrm{M}\right)$, IBAN+GGOH $\left(3 \times 10^{-5} \mathrm{M}\right)$, IBAN+FOH $\left(3 \times 10^{-5} \mathrm{M}\right)$ or IBAN+MEV $\left(10^{-4} \mathrm{M}\right)$ on Ang II-induced intracellular oxidation in VSMCs from SHRs. Data are presented as the mean \pm standard error of the mean ( $\mathrm{n}=5$ ). A and $\mathrm{C}$ : * $\mathrm{P}<0.05$, vs. WKY group; ${ }^{* *} \mathrm{P}<0.01$, vs. WKY group; ${ }^{\#} \mathrm{P}<0.05$, vs. SHR control group; ${ }^{\# \#} \mathrm{P}<0.01$, vs. SHR control or $\mathrm{SHR}$ group, ${ }^{\dagger} \mathrm{P}<0.05$, vs. WKY control group; ${ }^{\dagger \dagger} \mathrm{P}<0.01$, vs. WKY control group; B and E: ${ }^{* *} \mathrm{P}<0.01$, vs. control; ${ }^{\# \#} \mathrm{P}<0.01$, vs. Ang II, ${ }^{\dagger} \mathrm{P}<0.01$, vs. Ang II+IBAN group. SHRs, spontaneously hypertensive rats; WKY rats, Wistar-Kyoto rats; VSMCs, vascular smooth muscle cells; ROS, reactive oxygen species; IBAN, ibandronate; Ang II, angiotensin II; GGOH, geranylgeraniol; FOH, farnesol; MEV, mevalonate.

$24 \mathrm{~h}$ with vehicle or with $10^{-8}-10^{-5} \mathrm{M}$ IBAN, followed by $3 \mathrm{~h}$ incubation with $10^{-7} \mathrm{M}$ Ang II. Incubation of the VSMCs with IBAN alone had no significant effect on basal ROS production, whereas pretreatment with IBAN significantly reduced Ang II-induced ROS production in a concentration-dependent manner (Fig. 3B).

To investigate whether decreased ROS was observed in vivo, 10-week-old SHRs were provided with either standard chow or standard chow supplemented with IBAN for 30 days. Subsequently, the vascular production of ROS was assessed in isolated aortic segments. The production of $\mathrm{O}_{2}{ }^{-}$in the aortic segments from the SHRs was significantly higher, compared with that of the age-matched WKY rats (Fig. 3C). Pretreatment of the vessels with IBAN decreased $\mathrm{O}_{2}{ }^{-}$production in the segments from the hypertensive animals (265.0 \pm 21.0 , vs. $129.7 \pm 20.5 \%$ ), confirming the involvement of FPP synthase on ROS production in this strain.

Regulation of oxidative stress by IBAN. To determine whether the reversal of excess oxidative stress in SHR VSMCs by IBAN 
$\mathbf{A}$

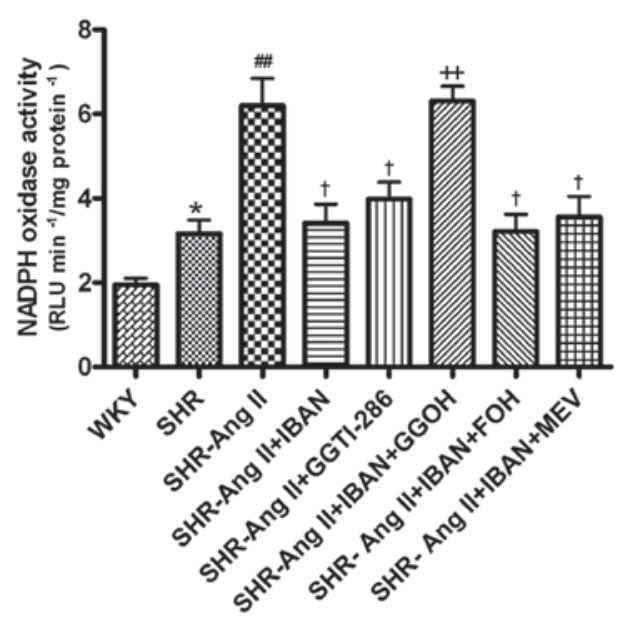

B

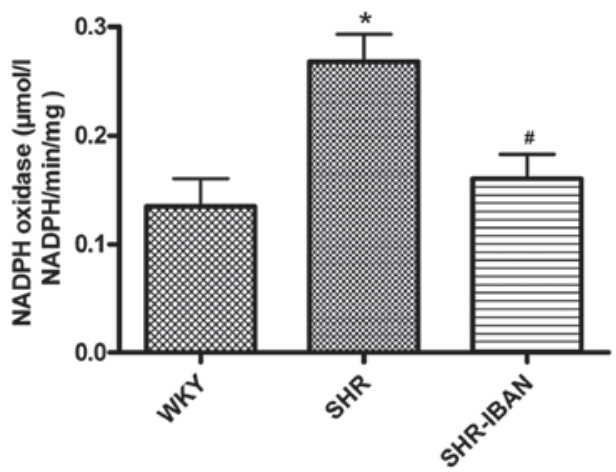

Figure 4. Effects of IBAN on NADPH oxidase activity in homogenates from VSMCs and aortic rings from SHRs and WKY rats. (A) VSMCs from SHRs were preincubated for $24 \mathrm{~h}$ with vehicle, IBAN $\left(10^{-5} \mathrm{M}\right)$, GGTI-286 $\left(10^{-5} \mathrm{M}\right)$, IBAN+GGOH $\left(3 \times 10^{-5} \mathrm{M}\right)$, IBAN+FOH $\left(3 \times 10^{-5} \mathrm{M}\right)$ or IBAN+MEV $\left(10^{-4} \mathrm{M}\right)$, followed by $3 \mathrm{~h}$ co-incubation with or without $10^{-7} \mathrm{M}$ Ang II. VSMCs from WKY rats were used as controls. (B) Vascular NADPH oxidase activity was assessed in isolated aortic segments of control and IBAN-treated SHRs. Data are presented as the mean \pm standard error of the mean $(n=5)$. A: ${ }^{*} \mathrm{P}<0.05$, vs. WKY group; ${ }^{\# \#} \mathrm{P}<0.01$, vs. SHR group; ${ }^{\circ} \mathrm{P}<0.05$, vs. SHR-Ang II group; ${ }^{++} \mathrm{P}<0.01$, vs. SHR-Ang II+IBAN group; B: ${ }^{*} \mathrm{P}<0.05$, vs. WKY group ${ }^{\#} \mathrm{P}<0.05$, vs. SHR group. SHRs, spontaneously hypertensive rats; WKY rats, Wistar-Kyoto rats; VSMCs, vascular smooth muscle cells; IBAN, ibandronate; Ang II, angiotensin II; GGOH, geranylgeraniol; FOH, farnesol; MEV, mevalonate; NADPH, nicotinamide adenine dinucleotide phosphate.

is associated with the MEV pathway in the present study, the VSMCs were treated with with IBAN and GGOH, FOH or $\operatorname{MEV}\left(10^{-5} \mathrm{M}, 3 \times 10^{-5} \mathrm{M}, 3 \times 10^{-5} \mathrm{M}\right.$ and $10^{-4} \mathrm{M}$, respectively). A representative microscopic scan is shown in Fig. 3D, and the data analysis for five separate experiments is shown in Fig. 3E. The results showed that neither FOH nor MEV altered the effect of IBAN on Ang II-induced $\left(10^{-7} \mathrm{M}\right)$ ROS production $(101.6 \pm 1.6$ and $114.6 \pm 6.8$, respectively, vs. $98.9 \pm 4.4 \%$; $\mathrm{P}>0.05)$, however, GGOH partly reversed the effect of ROS production $(197.1 \pm 8.3$, vs. $98.9 \pm 4.4 \% ; \mathrm{P}<0.01)$. It was found that GGTI-286, which regulates Rho geranylgeranylation, mimicked the inhibitory effect of IBAN on Ang II-induced ROS in the SHR VSMCs. Furthermore, the Rac1 inhibitor also significantly inhibited the increased production of ROS in the group treated with Ang II (Fig. 3D and E).

NADPH oxidase activity is increased in VSMCs and aortic rings from SHRs. The basal NADPH oxidize activity was significantly higher in the VSMCs from the 10-week-old SHRs, compared with the age-matched WKY rats (Fig. 4A). NADPH-stimulated production of $\mathrm{O}_{2}^{-}$in the SHR VSMCs was significantly enhanced (2-fold) when the cells were stimulated with Ang II $\left(10^{-7} \mathrm{M}\right)$. Pretreatment with IBAN $\left(10^{-5} \mathrm{M}\right)$ significantly reduced the Ang II-mediated activation of NADPH oxidase, and GGTI-286 $\left(10^{-5} \mathrm{M}\right)$ mimicked the inhibitory effect. Accordingly, neither FOH nor MEV $\left(3 \times 10^{-5} \mathrm{M}\right.$ and $10^{-4} \mathrm{M}$, respectively) affected the effect of IBAN on Ang II-induced enzyme activity, however, GGOH $\left(3 \times 10^{-5} \mathrm{M}\right)$ completely reversed this effect. The NADPH-stimulated $\mathrm{O}_{2}$ production in the endothelium-intact aortic rings was also significantly enhanced in the SHRs, compared with that in the WKY rats (Fig. 4B). Enzyme activity was significantly inhibited by $10^{-5} \mathrm{M}$ IBAN (by $40.3 \%$ ) in the aortic rings.

IBAN inhibits Racl activation. Treatment with Ang II $\left(10^{-7} \mathrm{M}\right)$ increased Racl GTP-binding activity 2.3-fold (Fig. 5A). Pre-incubation of the VSMCs with IBAN $\left(10^{-5} \mathrm{M}\right)$ completely prevented the Ang II-mediated increase of Rac1 activity (105.0 \pm 13.2 , vs. $225.0 \pm 14.4 \%$; P $<0.01)$. Similarly, GGTI-286 $\left(10^{-5} \mathrm{M}\right)$ inhibited the Ang II-induced activation of Rac1. However, in the presence of GGOH $\left(3 \times 10^{-5} \mathrm{M}\right)$, but not FOH $\left(3 \times 10^{-5} \mathrm{M}\right)$ or MEV $\left(10^{-4} \mathrm{M}\right)$, the inhibitory effect of IBAN against the activation of Racl by Ang II was markedly reversed to $210.7 \pm 11.0 \%$. Similarly, the levels of activated Rac1 were also significantly higher in the SHR aortas, compared to those in the WKY rats (2.60-fold; $\mathrm{P}<0.01$; Fig. 5B). Treatment with IBAN $(1 \mathrm{mg} / \mathrm{kg} /$ day $)$ decreased the levels of GTP-Racl. The total expression levels of Rac1 were examined using immunoblotting. No significant differences in the total expression levels of Rac1 were observed among the VSMCs and aortas in the above groups.

IBAN inhibits the expression of $p 47 p h o x$. The in vitro data showed that the expression of p47phox did not change in response to Ang II (data not shown). However, the results of the immunoblotting showed that Ang II $\left(10^{-7} \mathrm{M}\right)$ induced the translocation of subunits, which was indicated by increases in the relative level of membrane-bound $\mathrm{p} 47 \mathrm{phox}$ in the SHR VSMCs, and this effect was inhibited by IBAN and GGTI-286 $\left(10^{-5} \mathrm{M}\right)$. As Ang II was incubated for $3 \mathrm{~h}$, the expression of p47phox may also have been affected. Similar to Rac1 activity, the inhibitory effect of IBAN against the increased membrane-bound expression of p47phox subunits by Ang II was markedly reversed in the presence of GGOH $\left(3 \times 10^{-5} \mathrm{M}\right)$, but not FOH $\left(3 \times 10^{-5} \mathrm{M}\right)$ or MEV $\left(10^{-4} \mathrm{M}\right)$, respectively (Fig. 6A). Similarly, the protein levels of p47phox in the cytoplasmic and membrane fractions were higher in the SHR aortas, compared with those in the WKY rats. Treatment with IBAN $(1 \mathrm{mg} / \mathrm{kg} / \mathrm{day})$ also decreased the levels of this protein in the SHR aortas (Fig. 6B).

\section{Discussion}

Excess $\mathrm{O}_{2}^{-}$generation is involved in the inactivation of $\mathrm{NO}$ associated with endothelial dysfunction in clinical and experimental hypertension (1-3). The activation of the angiotensin AT1 receptor by Ang II in vascular cells is one of the most notable mechanisms of ROS production in vitro and 
A
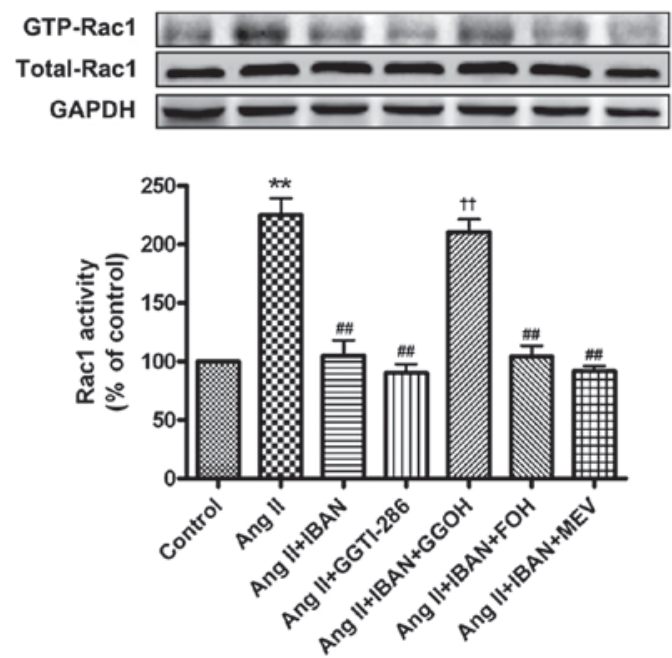

B
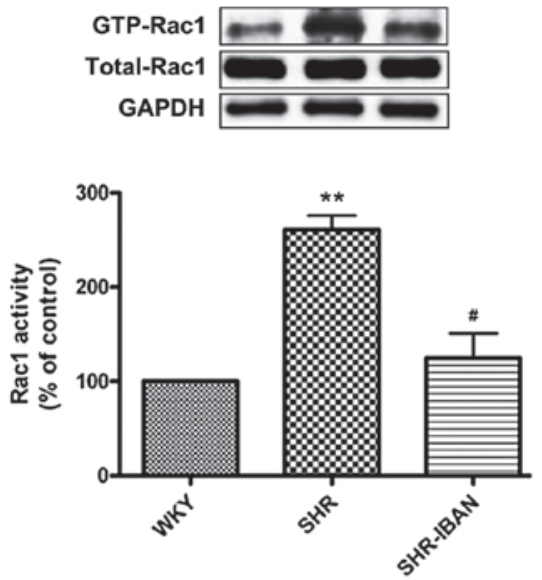

Figure 5. Effects of IBAN treatment on the activation and expression of Rac1. Rac1 activity was examined using a pull-down assay (upper panel). Western blot analysis was used to determine the total level of Rac1 (middle panel) in the same lysates. GAPDH protein was used as the endogenous control for each sample (lower panel). (A) Vascular smooth muscle cells from SHRs were preincubated for $24 \mathrm{~h}$ with vehicle, IBAN $\left(10^{-5} \mathrm{M}\right), \mathrm{GGTI}-286\left(10^{-5} \mathrm{M}\right)$, IBAN+GGOH $\left(3 \times 10^{-5} \mathrm{M}\right), \mathrm{IBAN}+\mathrm{FOH}\left(3 \times 10^{-5} \mathrm{M}\right)$ or IBAN+MEV $\left(10^{-4} \mathrm{M}\right)$, followed by a $3 \mathrm{~h}$ co-incubation with or without $10^{-7} \mathrm{M}$ Ang II. (B) Activity and expression of Rac1 in aortas were examined. Values are presented as the mean \pm standard error of the mean, and are representative of four independent experiments. A: ${ }^{* *} \mathrm{P}<0.01$, vs. control; ${ }^{* \#} \mathrm{P}<0.01$, vs. Ang II; ${ }^{~} \mathrm{P}<0.01$, vs. Ang II+IBAN group; $\mathrm{B}:{ }^{* *} \mathrm{P}<0.01$, vs. WKY group; ${ }^{*} \mathrm{P}<0.05$, vs. SHR group. SHRs, spontaneously hypertensive rats; WKY rats, Wistar-Kyoto rats; IBAN, ibandronate; Ang II, angiotensin II; GGOH, geranylgeraniol; FOH, farnesol; MEV, mevalonate; GAPDH, glyceraldehyde-3-phosphate dehydrogenase.

A
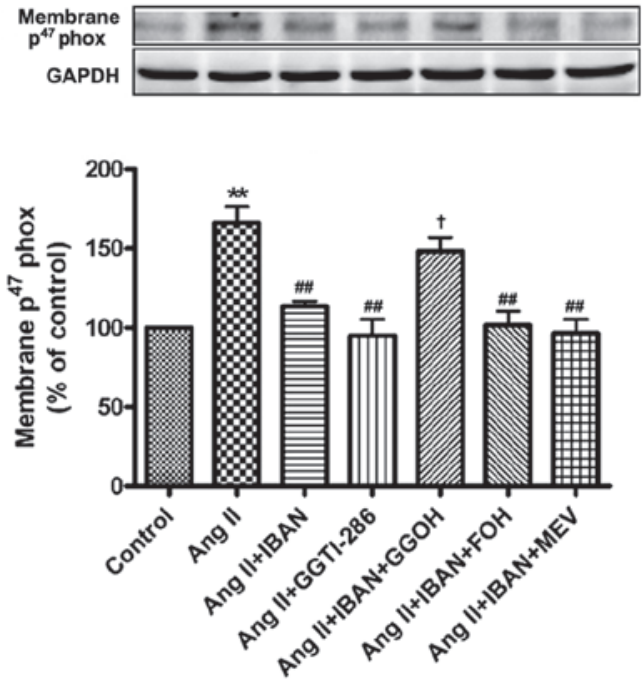

B
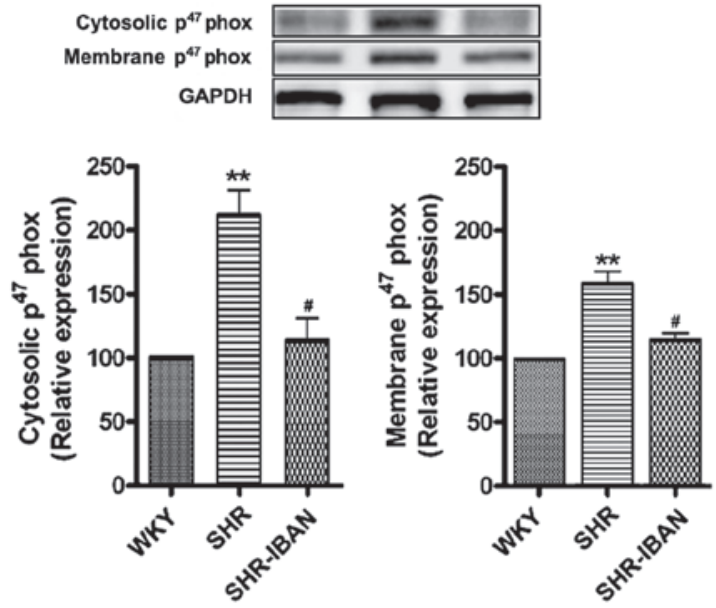

Figure 6. Effect of IBAN on the p47phox protein in cytosolic and membrane fractions from cultured VSMCs and aortic rings from SHRs and WKY rats. (A) VSMCs from SHRs were preincubated for $24 \mathrm{~h}$ with vehicle, IBAN $\left(10^{-5} \mathrm{M}\right)$, GGTI-286 $\left(10^{-5} \mathrm{M}\right)$, IBAN+GGOH $\left(3 \times 10^{-5} \mathrm{M}\right)$, IBAN+FOH $\left(3 \times 10^{-5} \mathrm{M}\right)$ or IBAN+ MEV $\left(10^{-4} \mathrm{M}\right)$, followed by $3 \mathrm{~h}$ co-incubation with or without $10^{-7} \mathrm{M}$ Ang II. (B) Protein leveles of p47phox in aortas were determined. Values are presented as the mean \pm standard error of the mean, and are representative of four independent experiments. A: ${ }^{* *} \mathrm{P}<0.01$, vs. control; ${ }^{\# \#} \mathrm{P}<0.01$, vs. Ang II; ${ }^{\dagger} \mathrm{P}<0.05$, vs. Ang II+IBAN group. B: ${ }^{* *} \mathrm{P}<0.01$, vs. WKY group; ${ }^{*} \mathrm{P}<0.05$, vs. SHR group. SHRs, spontaneously hypertensive rats; WKY rats, Wistar-Kyoto rats; VSMCs, vascular smooth muscle cells; IBAN, ibandronate; Ang II, angiotensin II; GGOH, geranylgeraniol; FOH, farnesol; MEV, mevalonate; GAPDH, glyceraldehyde-3-phosphate dehydrogenase. GAPDH, glyceraldehyde-3-phosphate dehydrogenase.

in vivo $(4,5)$. The abnormal elevation in Ang II occurs in SHRs, and they exhibit an exaggerated increase in circulating Ang II in response to stimuli (29). The present study found that the production of ROS, activity of NADPH oxidase and expression of the p47phox subunit were enhanced in the SHR aortas, as well as in the Ang II-stimulated VSMCs from the SHRs. In addition, a previous study confirmed that higher expression of $\mathrm{p} 47$ phox and increased $\mathrm{O}_{2}^{-}$production are localized predominantly to the smooth muscle layer in SHRs, compared with those in WKY rats (28). In the present study, the FPP synthase inhibitor, IBAN, exerted antioxidant effects in the SHR group in vivo and in vitro. These results indicated that these effects may be an important mechanism contributing to the prevention of endothelial dysfunction by IBAN.

$\mathrm{ACh}$ is used as a standard drug to estimate vascular endothelial function. It acts on muscarinic receptors and 


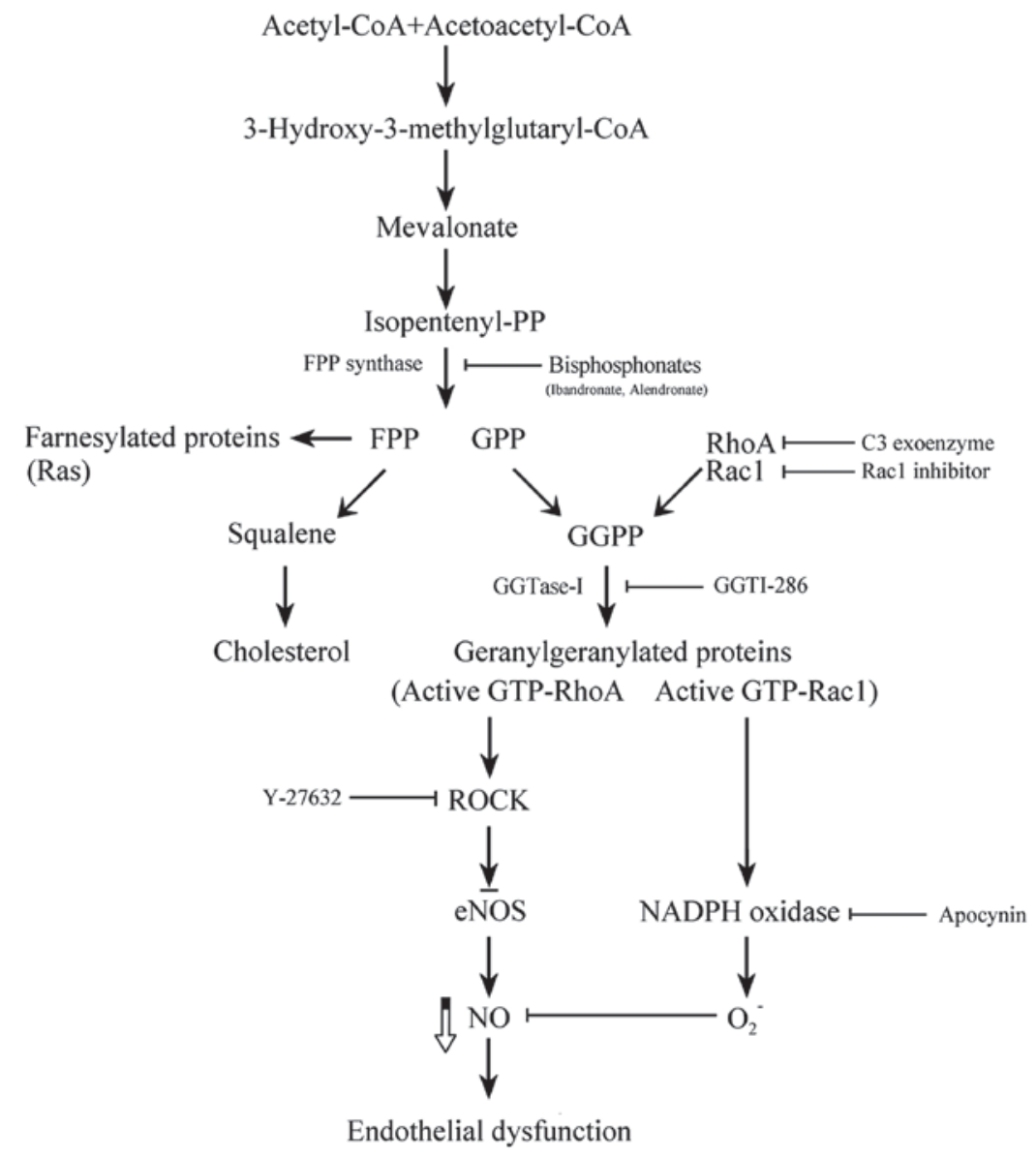

Figure 7. Diagrammatic presentation of the mevalonate pathway and ibandronate-induced endothelial protection process via regulation of isoprenoid intermediates and RhoA/ROCK and Rac1/NADPH oxidase activation. FPP synthase, farnesyl pyrophosphate; GGPP, geranylgeranyl pyrophosphate; ROCK, Rho-associated kinase; NO, nitric oxide; eNOS, endothelial nitric oxide synthase; NADPH, nicotinamide adenine dinucleotide phosphate.

induces the synthesis and release of several vasoactive factors, including NO and cyclooxygenase-derived vasodilators and vasoconstrictors, in endothelial cells. It is established that $\mathrm{NO}$ is the most important vasodilator released from the endothelium, and endothelium-dependent vasodilation is almost completely dependent on NO $(30,31)$. In the present study, the endothelium-independent relaxation induced by SNP was similar in the SHRs and WKY rats, and was unaffected by IBAN, indicating that the improved relaxation response by IBAN was due to changes in endothelium-derived NO bioavailability. In addition, L-NAME eradicated the differences in endothelium-dependent relaxation between the IBAN-treated and -untreated SHRs, suggesting that increased NO bioactivity was the cause of the amelioration of endothelial function. Furthermore, our previous report demonstrated that endothelial improvement by treatment with another bisphosphonate (FPP synthase inhibitor, alendronate) in SHRs had minimal involvement with the COX pathway (18).

Cells metabolize GGOH to GGPP, and FOH is metabolized to FPP (32). Incubation with GGOH, but not with FOH or MEV, partially reversed the improvement in the IBAN-induced endothelial relaxation response in isolated aortic rings in the SHRs, suggesting that the protective effect of inhibiting FPP synthase on endothelial function was associated, at least in part, with inhibition of the MEV pathway, particularly by suppressing small GTP-binding protein geranylgeranylation (Fig. 7). The small GTP-binding protein, Rac1, is important in the activation and assembly of NADPH oxidase $(10,11)$. The primary mechanism of action of the FPP synthase inhibitor is the depletion of isoprenoid intermediates, including GGPP (12-14), which is of importance for the post-translational geranylgeranylation of small Rho GTPase signaling proteins, including Racl and RhoA $(15,16)$.

Notably, the present study found a higher level of GTP-bound active Rac1, but a similar level of total Rac1, in the aortas from the SHRs, compared with those from the WKY rats. Furthermore, bisphosphonate treatment of the SHRs decreased the level of active Rac1, but had no effect on the total expression of Rac1, demonstrating that the FPP synthase inhibitor only affected the activated process of Rac1 and RhoA in vivo (18), possibly by inhibiting their isoprenylation. Pretreatment with GGTI-286, C3 exoenzyme, Y-27632, Rac1 inhibitor or apocynin mimicked the improved effect of IBAN on vascular relaxation, suggesting that the improved endothelial effect of bisphosphonates may be mediated by the RhoA/eNOS and Rac1/NADPH oxidase pathways.

Similarly, incubation with GGOH, but not FOH or MEV partially reversed the IBAN-induced inhibition of excess ROS generation induced by Ang II in vitro, suggesting that the antioxidative effect of IBAN on Ang II stimulation may be mediated, at least in part, by the suppression of GGPP. Of note, consistent with previous reports, the present study 
found a higher level of GTP-bound active Rac1, which was comparable to the level of total Racl in VSMCs in response to Ang II (33). Consistent with the in vivo experiments, IBAN treatment led to a similar impairment of active Rac1, however, there were no effects on total protein levels. Consistently, the present data showed that the IBAN-induced decrease in the activated form of Racl was reversed by $\mathrm{GGOH}$, but not by $\mathrm{FOH}$ or $\mathrm{MEV}$, as was the excess oxidative response phenotype, suggesting that inhibiting FPP synthase affected only the activated form of Racl in the VSMCs by inhibiting GGPP and consequently suppressing the geranylgeranylation-dependent translocation of Rac1 from the cytosol to the cell membrane.

Notably, GGTI-286, a specific inhibitor of geranylgeranyl-transferase (GGTase) I for geranylgeranylation, which reduces Ang II-induced Racl activity, inhibited the excess oxidative response evoked by Ang II. This result was supported by a previous report of Zuckerbraun et al, in that inhibiting GGTase I prevents the excess oxidative phenotype induced by Ang II (34). Furthermore, the Rac1 inhibitor attenuated the production of ROS induced by Ang II. Taken together, these results further supported the hypothesis that preventing Rac1 activation and geranylgeranylation is essential for protection against Ang II-induced oxidative response in VSMCs by IBAN.

Hypertension increases mechanical strain in the vessel wall. Mechanical stretch leads to ERK activation via Rho/ROCK (35). The Rho/ROCK pathway is substantially involved in the pathogenesis of hypertension and hypertensive vascular disease (36). In our previous studies, it was found that the administration of a high-dose of FPP synthase inhibitor (alendronate; $10 \mathrm{mg} / \mathrm{kg} /$ day) upstream of the signaling target of Rho/ROCK reduced the SBP and MAP in SHRs (18). The lowering of blood pressure with nonhypotensive doses of fasudil also significantly suppressed vascular lesion formation, in addition to normalization of the endothelial production of superoxide anions and resultant improvement in endothelial vasodilator function (37). In the present study, it was found that $1 \mathrm{mg} / \mathrm{kg} / \mathrm{day}$ IBAN had no effect on blood pressure regulation, thus the beneficial effect on endothelial dysfunction was independent of blood pressure.

In general, the dose used in the rat experiments were 50-100 times higher than those used in studies involving human (38). Although the dose of IBAN used in the present study ( $1 \mathrm{mg} / \mathrm{kg} /$ day) was high, compared with the quoted oral does in humans of $150-600 \mathrm{mg} / \mathrm{month}$, it remained with the range of 50-100 times higher than the human dose. Of note, the present study was heavily based on pharmacological tools, and the use of genetic-knockout mice would further improve the quality of results in the future.

In conclusion, FPP synthase-catalyzed isoprenoid intermediates are necessary for the appropriate functioning of RhoA and Rac1; the former negatively regulated eNOS expression and activity, and the latter positively regulated the expression and activity of NADPH oxidase. Therefore, inhibiting FPP synthase improved endothelial dysfunction in the SHRs, which was, at least in part, associated with reduced GTP-bound active Rac1 and subsequent reduced NADPH oxidase activity.

\section{Acknowledgements}

This study was financially supported by the National Natural Sciences Foundation of China (grant nos. 81200191, 30470715 and 30870939), the Research Fund for the Doctoral Program of Higher Education of China (grant no. 20040335118), the International Collaboration Project of Science and Technology Department of Zhejiang Province (grant no. 2011C14027) and the National Natural Sciences Foundation of China (grant no. 81400277).

\section{References}

1. Cai $\mathrm{H}$ and Harrison DG: Endothelial dysfunction in cardiovascular diseases: The role of oxidant stress. Circ Res 87: 840-844, 2000.

2. Sánchez M, Galisteo M, Vera R, Villar IC, Zarzuelo A, Tamargo J, Pérez-Vizcaino F and Duarte J: Quercetin downregulates NADPH oxidase, increases eNOS activity and prevents endothelial dysfunction in spontaneously hypertensive rats. J Hypertens 24: 75-84, 2006.

3. Suzuki H, Swei A, Zweifach BW and Schmid-Schönbein GW: In vivo evidence for microvascular oxidative stress in spontaneously hypertensive rats. Hydroethidine microfluorography. Hypertension 25: 1083-1089, 1995.

4. Griendling KK, Minieri CA, Ollerenshaw JD and Alexander RW: Angiotensin II stimulates NADH and NADPH oxidase activity in cultured vascular smooth muscle cells. Circ Res 74: 1141-1148, 1994.

5. Rajagopalan S, Kurz S, Münzel T, Tarpey M, Freeman BA, Griendling KK and Harrison DG: Angiotensin II-mediated hypertension in the rat increases vascular superoxide production via membrane NADH/NADPH oxidase activation. Contribution to alterations of vasomotor tone. J Clin Invest 97: 1916-1923, 1996.

6. Babior BM: NADPH oxidase: An update. Blood 93: 1464-1476, 1999.

7. Griendling KK, Sorescu D and Ushio-Fukai M: NAD(P)H oxidase: Role in cardiovascular biology and disease. Circ Res 86: 494-501, 2000.

8. Suh YA, Arnold RS, Lassegue B, Shi J, Xu X, Sorescu D, Chung AB, Griendling KK and Lambeth JD: Cell transformation by the superoxide-generating oxidase Mox1. Nature 401: 79-82, 1999.

9. Xiao L, Pimentel DR, Wang J, Singh K, Colucci WS and Sawyer DB: Role of reactive oxygen species and NAD(P) $\mathrm{H}$ oxidase in alpha(1)-adrenoceptor signaling in adult rat cardiac myocytes. Am J Physiol Cell Physiol 282: C926-C934, 2002.

10. Dusi S, Donini M and Rossi F: Mechanisms of NADPH oxidase activation in human neutrophils: p67phox is required for the translocation of rac 1 but not of rac 2 from cytosol to the membranes. Biochem J 308: 991-994, 1995.

11. Rinckel LA, Faris SL, Hitt ND and Kleinberg ME: Rac1 disrupts p67phox/p40phox binding: A novel role for Rac in NADPH oxidase activation. Biochem Biophys Res Commun 263: 118-122, 1999.

12. Russell RG, Watts NB, Ebetino FH and Rogers MJ: Mechanisms of action of bisphosphonates: Similarities and differences and their potential influence on clinical efficacy. Osteoporos Int 19: 733-759, 2008.

13. Szkopińska A and Plochocka D: Farnesyl diphosphate synthase; regulation of product specificity. Acta Biochim Pol 52: 45-55, 2005.

14. Scita G, Tenca P, Frittoli E, Tocchetti A, Innocenti M, Giardina G and Di Fiore PP: Signaling from Ras to Rac and beyond: Not just a matter of GEFs. EMBO J 19: 2393-2398, 2000.

15. Takai Y, Sasaki T and Matozaki T: Small GTP-binding proteins. Physiol Rev 81: 153-208, 2001.

16. Rolfe BE, Worth NF, World CJ, Campbell JH and Campbell GR: Rho and vascular disease. Atherosclerosis 183: 1-16, 2005.

17. Chen GP, Yao L, Lu X, Li L and Hu SJ: Tissue-specific effects of atorvastatin on 3-hydroxy-3-methylglutarylcoenzyme A reductase expression and activity in spontaneously hypertensive rats. Acta Pharmacol Sin 29: 1181-1186, 2008. 
18. Chen GP, Li L, Yang Y, Fu M, Yao L, Wu T, Zhang XQ and $\mathrm{Hu}$ SJ: Chronic inhibition of farnesyl pyrophosphate synthase improves endothelial function in spontaneously hypertensive rats. Biochem Pharmacol 80: 1684-1689, 2010.

19. Institute of Laboratory Animal Resources (US). Committee on Care, Use of Laboratory Animals, and National Institutes of Health (US). Division of Research Resources: Guide for the care and use of laboratory animals. 8th edition. National Academies Press, Washington, DC, 2011.

20. Moomaw JF and Casey PJ: Mammalian protein geranylgeranyltransferase. Subunit composition and metal requirements. J Biol Chem 267: 17438-17443, 1992.

21. Hayashi M, Sakata M, Takeda T, Tahara M, Yamamoto T, Minekawa R, Isobe A, Tasaka K and Murata Y: Hypoxia up-regulates hypoxia-inducible factor-1alpha expression through RhoA activation in trophoblast cells. J Clin Endocrinol Metab 90: 1712-1719, 2005.

22. Woods A, Wang G and Beier F: RhoA/ROCK signaling regulates Sox9 expression and actin organization during chondrogenesis. J Biol Chem 280: 11626-11634, 2005.

23. Gao Y, Dickerson JB, Guo F, Zheng J and Zheng Y: Rational design and characterization of a Rac GTPase-specific small molecule inhibitor. Proc Natl Acad Sci USA 101: 7618-7623, 2004.

24. Hamilton CA, Brosnan MJ, McIntyre M, Graham D and Dominiczak AF: Superoxide excess in hypertension and aging: A common cause of endothelial dysfunction. Hypertension 37: 529-534, 2001

25. Kakoki M, Hirata Y, Hayakawa H, Nishimatsu H, Suzuki Y, Nagata D, Suzuki E, Kikuchi K, Nagano T and Omata M: Effects of vasodilatory beta-adrenoceptor antagonists on endothelium-derived nitric oxide release in rat kidney. Hypertension 33: 467-471, 1999.

26. Battle T, Arnal JF, Challah M and Michel JB: Selective isolation of rat aortic wall layers and their cell types in culture-application to converting enzyme activity measurement. Tissue Cell 26 943-955, 1994.

27. Xiao J, Cao H, Liang D, Liu Y, Zhang H, Zhao H, Liu Y, Li J, Yan B, Peng L, et al: Taxol, a microtubule stabilizer, prevents ischemic ventricular arrhythmias in rats. J Cell Mol Med 15: 1166-1176, 2011

28. Lodi F, Cogolludo A, Duarte J, Moreno L, Coviello A, Peral De Bruno M, Vera R, Galisteo M, Jiménez R, Tamargo J and Perez-Vizcaino F: Increased NADPH oxidase activity mediates spontaneous aortic tone in genetically hypertensive rats. Eur J Pharmacol 544: 97-103, 2006.
29. Bolterman RJ, Manriquez MC, Ortiz Ruiz MC, Juncos LA and Romero JC: Effects of captopril on the renin angiotensin system, oxidative stress, and endothelin in normal and hypertensive rats. Hypertension 46: 943-947, 2005.

30. Vanhoutte PM and Miller VM: Heterogeneity of endothelium-dependent responses in mammalian blood vessels. J Cardiovasc Pharmacol 7 (Suppl 3): S12-S23, 1985.

31. Nagao T, Illiano S and Vanhoutte PM: Heterogeneous distribution of endothelium-dependent relaxations resistant to NG-nitro-L-arginine in rats. Am J Physiol 263: H1090 H1094, 1992.

32. Fisher JE, Rogers MJ, Halasy JM, Luckman SP, Hughes DE, Masarachia PJ, Wesolowski G, Russell RG, Rodan GA and Reszka AA: Alendronate mechanism of action: Geranylgeraniol, an intermediate in the mevalonate pathway, prevents inhibition of osteoclast formation, bone resorption, and kinase activation in vitro. Proc Natl Acad Sci USA 96: 133-138, 1999.

33. Zeng L, Xu H, Chew TL, Chisholm R, Sadeghi MM, Kanwar YS and Danesh FR: Simvastatin modulates angiotensin II signaling pathway by preventing Rac1-mediated upregulation of p27. J Am Soc Nephrol 15: 1711-1720, 2004.

34. Zuckerbraun BS, Barbato JE, Hamilton A, Sebti S and Tzeng E: Inhibition of geranylgeranyltransferase I decreases generation of vascular reactive oxygen species and increases vascular nitric oxide production. J Surg Res 124: 256-263, 2005.

35. Numaguchi K, Eguchi S, Yamakawa T, Motley ED and Inagami T: Mechanotransduction of rat aortic vascular smooth muscle cells requires RhoA and intact actin filaments. Circ Res 85: 5-11, 1999.

36. Mukai Y, Shimokawa H, Matoba T, Kandabashi T, Satoh S, Hiroki J, Kaibuchi K and Takeshita A: Involvement of Rho-kinase in hypertensive vascular disease: A novel therapeutic target in hypertension. FASEB J 15: 1062-1064, 2001.

37. Higashi M, Shimokawa H, Hattori T, Hiroki J, Mukai Y, Morikawa K, Ichiki T, Takahashi S and Takeshita A: Long-term inhibition of Rho-kinase suppresses angiotensin II-induced cardiovascular hypertrophy in rats in vivo: Effect on endothelial NAD(P)H oxidase system. Circ Res 93: 767-775, 2003.

38. Susic D, Varagic J, Ahn J, Slama M and Frohlich ED: Beneficial pleiotropic vascular effects of rosuvastatin in two hypertensive models. J Am Coll Cardiol 42: 1091-1097, 2003. 